\title{
Um teatro das ideias, com muito humor
}

\section{Christine Zurbach}

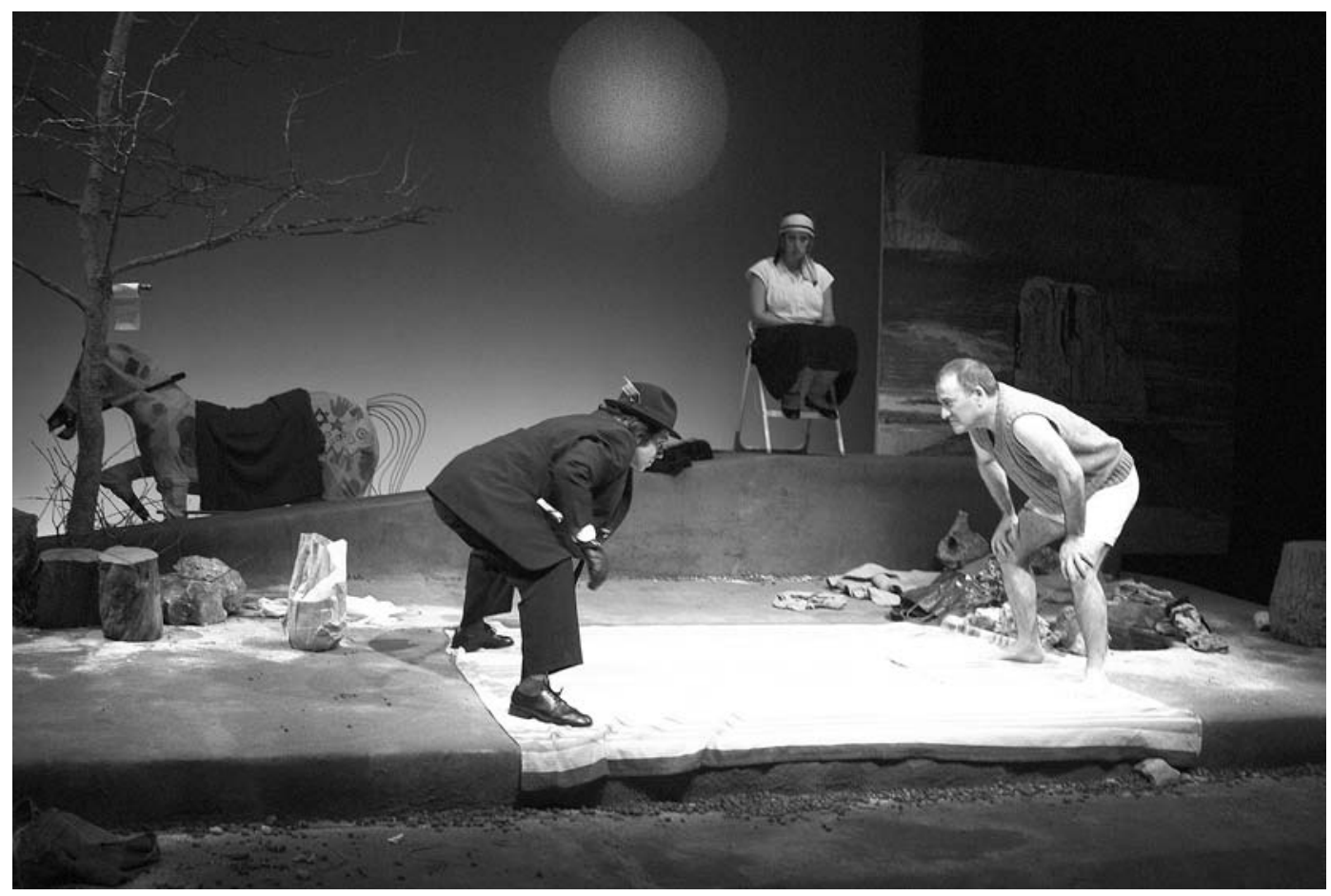

Weisman ecara vermelha de George Tabori, enc. Fernando Mora Ramos, Teatro da Rainha 2008 (Carlos Borges, Bárbara Andrez e Fernando Mora Ramos), fot. Margarida Araújo.

Titulo: Weisman e cara vermelha (1991). Autor: George Tabori. Tradução: Carlos Borges. Encenação: Fernando Mora Ramos. Acompanhamento dramatúrgico:Isabel Lopes. Cenografia e figurinos: José Carlos Faria. Banda sonora: Carlos Alberto Augusto. Iluminação: Fernando Mora Ramos e Carlos Assunção. Interpretação: Bárbara Andrez, Fernando Mora Ramos, Carlos Borges, José Carlos Faria / Octávio Teixeira. Produção: Teatro da Rainha. Local e data de estreia: Antiga Lavandaria do Centro Hospitalar das Caldas da Rainha, 13 de Março de 2008.

Falecido em Berlim em 2007, o dramaturgo e encenador húngaro de nascimento George Tabori pertenceu ao grupo dos artistas e intelectuais alemães que, como Brecht mas com o "acréscimo" da sua origem judaica, abandonaram a Alemanha perante a ascensão do nazismo nos anos 30. No seu longo exílio, entre 1935 e 1971, data do seu regresso à Alemanha Federal, passou pelos Estados Unidos onde traduziu para inglês a obra de Brecht e iniciou a sua carreira no cinema e no teatro. Deixa uma obra escrita multifacetada, composta por géneros diversos, entre ensaios, romances, argumentos para cinema e textos de teatro.

É precisamente na riqueza potencializada por um tal cruzamento de modelos de escrita, no hibridismo de características próprias de várias formas artísticas, que a encenação do Teatro da Rainha enraiza o espectáculo que concebeu a partir da peça de Tabori, Weisman e cara vermelha, designada em termos genológicos pelo próprio autor como "western judeu". É nesse território que reside o aspecto central da proposta dramatúrgica aqui desenvolvida, claramente inscrita numa obra que aposta na sua filiação no género cinematográfico, e também literário, do western em que predomina a figura do combate, aqui explorada sobretudo no plano espiritual e moral, entre dois homens que entram em confronto apesar de serem ambos vencidos da sociedade e da História.

Numa entrevista dada em 1990 à revista Theater Heute, e acertadamente publicada no programa que, como excelente hábito da companhia, acompanha o espectáculo, Tabori esclarece as circunstâncias da escrita da peça. De uma novela que Ihe foi inspirada, ainda nos Estados Unidos, pelo ambiente político-ideológico criado pelas tensões raciais no fim dos anos 60 em que as próprias minorias 

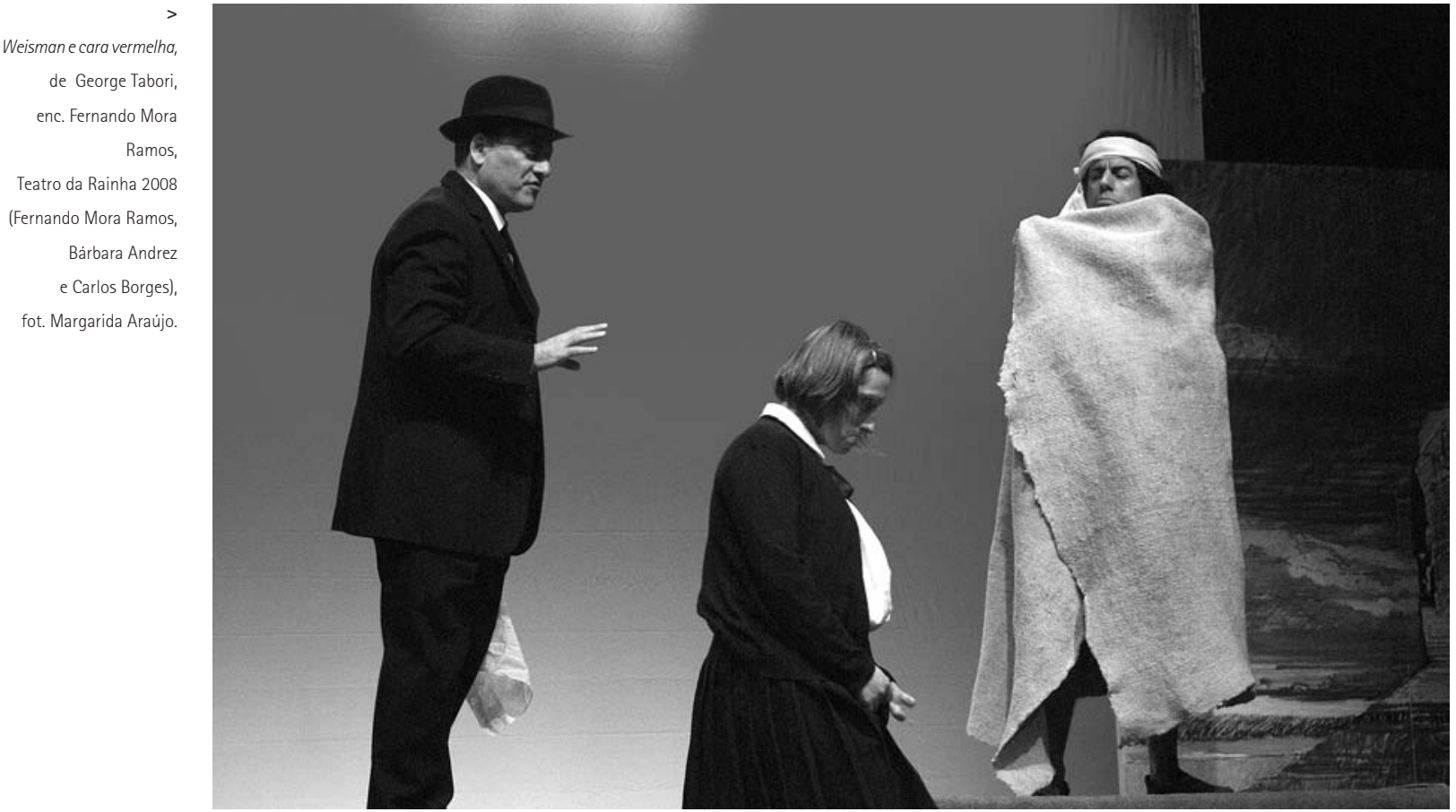

radicalizaram as suas posições relativamente aos seus apoios, cortando "especialmente com os intelectuais judeus de Nova lorque", o escritor tirou uma peça de teatro sobre as contradições entre determinadas figuras de vítimas da opressão de inspiração racial em que se podem seguir os passos de uma luta entre dois indivíduos, arbitrada por uma terceira personagem que representa também o prémio final: Rute, a filha deficiente, adolescente crescida e sensivel, nascida, segundo o seu progenitor, do pecado da carne impulsivamente cometido na mesa da cozinha.

Encenada pelo próprio autor em Viena em 1990, a peça é bem representativa da indesmentivel eficiência pragmática da dramaturgia de Tabori que explora aqui a fórmula simples do encontro entre duas personagens e do conflito que suscita o preconceito racista que ambos transportam de modo algo inconsciente, até ao desfecho da acção. Na verdade, o significado simbólico da peça mantém-se presente na proposta dramatúrgica escolhida por Tabori, na medida em que vencedor e vencido se defrontam num terreno quase tão abstracto como o ringue do boxe, o da mítica paisagem construída do deserto californiano, tão amplamente divulgada (e esvaziada por isso de qualquer realismo) pelas produções da indústria cinematográfica de Hollywood.

Empenhada desde a sua fundação num modo coerente de conceber a prática do teatro como era entendida por Vitez, e é recordada pelo encenador Mora Ramos, como "teatro das ideias", a companhia do Teatro da Rainha propõe ao espectador uma leitura ao mesmo tempo política, ética e poética da obra de Tabori. Política, no desafio que encerra a delicada temática ideológica (no sentido de expressão de ideias) representada pelo drama do protagonista, o judeu americano Weisman (o homem branco), cujo caminho atravessa o de um representante típico de uma minoria, o (pseudo)Índio chamado Cara Vermelha, com quem trava um derradeiro combate. $\mathrm{Na}$ verdade, o Índio não o é: é Joe Cuaoléu, antisemita e reparador de postes de electricidade no deserto, branco que traz no corpo um cosmético cor de cobre, que não consegue lavar sem ficar com a pele em carne viva, mas que the permitiu passar a noite, a salvo, num hotel de Albuquerque frequentado por índios... Ética, na medida em que esse mesmo combate não opõe o bom e o mau como no western, mas obriga o espectador a reconsiderar a personagem do pecador, a pôr em questão a bondade que estaria do outro lado, aquela que, como explica Tabori, leva Caim a aniquilar Abel por causa da insuportável bondade do irmão. Poética, no tratamento artístico dado à montagem do texto, na opção pelo aprofundamento das potencialidades teatrais de uma escrita e de uma dramaturgia que resultam, no espectáculo, num objecto visual largamente alimentado pelo universo de imagens nascidas da especificidade da experiência biográfica e literária do dramaturgo George Tabori.

Fazendo justiça à qualidade literária do texto, que encontra na tradução realizada por Carlos Borges uma reescrita teatralmente eficaz, nos diálogos como nas longas narrativas do pseudo-índio, e sobretudo no duelo verbal final, a proposta do Teatro da Rainha realça a importância da experiência do autor na construção de textos narrativos irmanados com guiões para o cinema. Num recorte em oito quadros, a acção recupera o modelo convencional, historicamente consagrado, de toda a fiç̧ão que (ainda) visa contar uma história, entendida como sequência encadeada de acções logicamente organizadas, com personagens ao mesmo tempo individualizadas e simbólicas, num espaço e num tempo definidos. Juntandose-Ihe o molde clássico da tragédia como expressão da fatalidade do destino humano, aliada ao fundo comum entre todos de referências culturais biblicas e judaicas, a história contada evolui passo a passo, encaminhando Weisman para "o último assalto", insistindo na reiteração de conotações tragicómicas onde são reconheciveis a auto-ironia própria do dito humor judeu, excelentemente presente no jogo dos actores.

Numa progressão cronológica sem rupturas, a peça vai confirmando a premonição inscrita logo na imagem inicial da condenação da personagem do judeu. No cenário, 


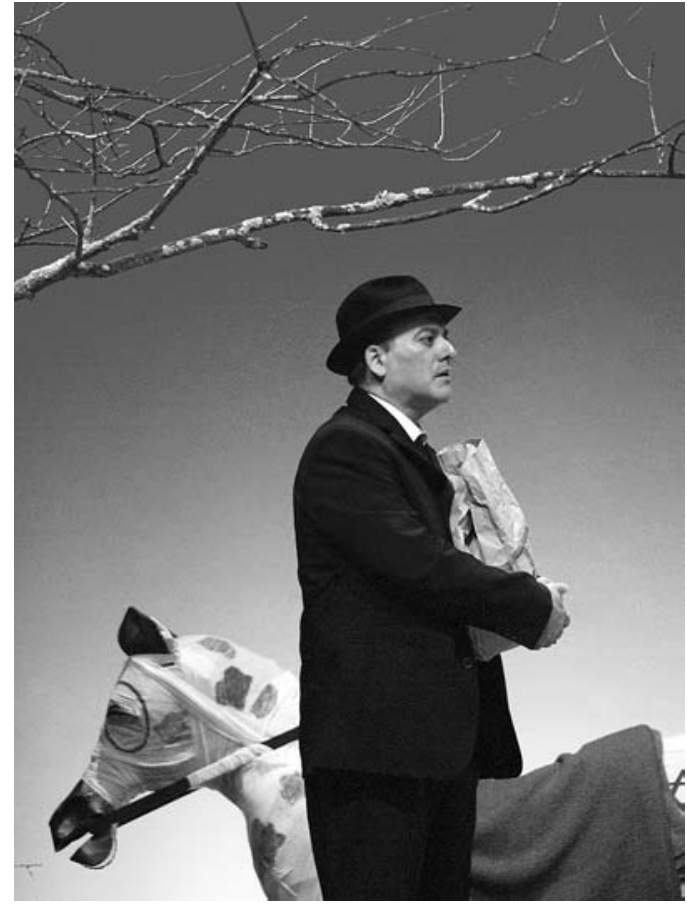

a morte que o espera surge simbolizada no abutre, magnífico adereço a que também é permitido "intervir" na acção, que aparece poisado na árvore ressequida do cenário desértico e que o espectador descobre assim que entra na sala. 0 deserto é exposto na sua tipologia imediatamente reconhecivel: ameaçador, é fielmente copiado dos décors hollywoodescos com o artifício colorido das Montanhas Rochosas pintadas pelo cenógrafo José Carlos Faria sobre dois biombos plantados de cada lado do palco, as pedras e a areia amarelada, os arbustos acastanhados, o céu sobre o ciclorama que passará do azul intenso, diurno, para o cair da noite com o inevitável luar esbranquiçado.

Do mesmo modo que o tempo, sem surpresa na sua progressão irreversivel para o final da acção, o espaço é concebido de modo a intensificar sinais inequívocos de desumanização. Só a caricata e invencivel esperança do seu pai, que reclama o mérito de ter sobrevivido à Depressão de 1929, a Hitler e à própria esposa..., pode estimular na filha, Rute, o sonho de regar flores imaginárias quando se está a aliviar atrás dos arbustos. Às imagens visuais juntam-se sinais sonoros, também eles associados ao espaço convencional: uma partitura sonora construida sobre a citação ou evocação das memoráveis bandas sonoras criadas por Ennio Morricone para Sérgio Leone, o som discreto da flauta do Índio e também o ruído dos cascos do cavalo ou canções, melopeias e orações judaicas vagamente esboçadas pelas personagens.

Contrariando o excesso do que é imediatamente banal e, por isso, reconhecivel na cenografia (na citação sublinhada até ao cliché), a estranheza necessária para suscitar a reflexão do espectador como recomenda a tradição brechtiana que aqui se adivinha, surge logo com o aparecimento das primeiras personagens, totalmente improváveis na paisagem de um western, e que, como verdadeiros aliens, contrariam as figuras convencionais da tipologia.

Em vez do cowboy ou do pistoleiro, entram em cena duas figuras recortadas na tela, que cambaleiam até ao

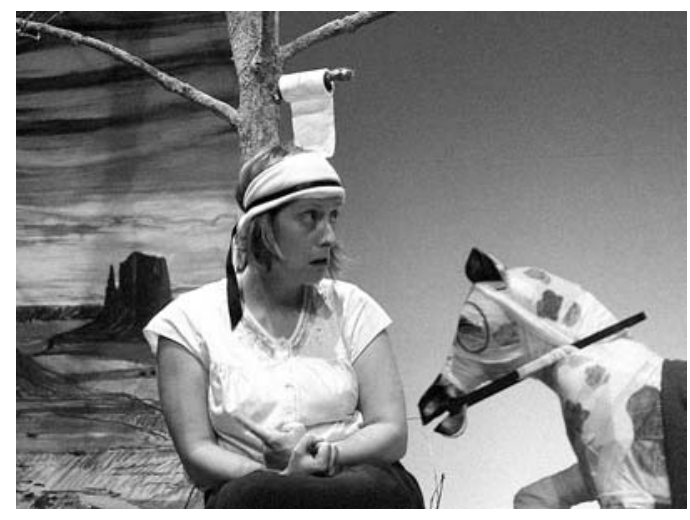

Weisman e cara vermelha, de George Tabori, enc. Fernando Mora Ramos, Teatro da Rainha 2008 (< Fernando Mora Ramos; > Bárbara Andrez ), fot. Margarida Araújo. $<>$

meio do palco, param e dão início à acção: um pai judeu viúvo, de luto, vestido a rigor com chapéu e gravata preta, figura irrisória - e muito humana - interpretada pelo actor e encenador Fernando Mora Ramos, e que perderá durante a peça qualquer ilusão sobre si mesmo e sobre a humanidade em geral; a filha, "bonita, apesar de mongolóide e de ter várias limitações", interpretada com um trabalho gestual e vocal rigoroso por Bárbara Andrez, uma personagem, supostamente frágil, de uma deficiente em luta pela sua própria vida. No cumprimento da promessa feita de espalhar as suas cinzas no local onde, segundo diz, ela foi feliz outrora, "à esquina da Riverside Drive com a 99", o judeu transporta, num saco de papel, a urna da mulher Bella, falecida "apesar dos milagres da ciência (...) de um dente de siso atrasado". Perderam-se ao desviaremse do seu caminho para Leste. Fragilizados, são assaltados por um caçador que, à falta de cavalos, Ihes rouba o carro. A esperança de uma salvação surge, mais tarde, com a chegada de uma figura localmente credivel: um Índio, montado num burro, mas que a pouco e pouco vai desvendar a sua verdadeira condição de homem branco que, para salvar a própria pele, se pintou de cor vermelha e usa tranças postiças e que continua disposto a lutar pela sua sobrevivência, a qualquer preço. Numa leitura ao mesmo tempo lúdica e inquietante da personagem, o actor Carlos Borges conduz, com as duas criaturas desamparadas, a inteligente demonstração construída pelo dramaturgo da inevitável ausência de solidariedade entre os oprimidos, aqui exposta sem ambiguidades, até ao derradeiro duelo (ou sua caricatura) que deve concluir todo o western digno desse nome.

Uma encenação que propõe, para o espectador contemporâneo, uma lição ao mesmo tempo didáctica ao reatar com a função primordial de um teatro de ideias - e humoristica - ainda que não desprovida de bastante amargura e até crueldade -, sobre a inelutável dimensão trágica do destino de quem nasce judeu, deficiente ou índio no mundo que é o nosso. 